\title{
EFFECTIVENESS OF NUTRITION EDUCATION INTERVENTION ON MATERNAL NUTRITIONAL KNOWLEDGE AMONG WOMEN OF CHILDBEARING AGE IN IKENNE LOCAL GOVERNMENT AREA OF OGUN STATE, NIGERIA
}

\author{
${ }^{* 1}$ Ngozi E. O., ${ }^{2}$ John E. P and ${ }^{1}$ Baderinwa T. J \\ ${ }^{1}$ Nutrition and Dietetics Department, School of Basic Medical Sciences, Babcock University, Ilishan-Remo, Ogun \\ State, Nigeria. \\ ${ }^{2}$ Department of Nutrition and Dietetics, College of Food Science and Human Ecology, Federal University of \\ Agriculture, Abeokuta, Ogun State. Nigeria. \\ P.M.B. 2240, Abeokuta, Ogun State, Nigeria.
}

*Corresponding Author: ngozie@ babcock.edu.ng

\begin{abstract}
Background: Nutrient inadequacy during childbearing age and pregnancy is a major cause of intrauterine growth retardation of the foetus leading to other long-term health problems such as non-communicable diseases in later years. More so, child malnutrition and mortality can be majorly attributed to improper infant and young child feeding practices.

Objective: This study was carried out to assess the effectiveness of nutrition education intervention on maternal nutritional knowledge among women of childbearing age in Ikenne Local Government Area of Ogun State.

Materials and Method: A descriptive cross-sectional research design was employed for this study and 115 women of childbearing age were selected using simple random sampling technique. Data were collected using a validated questionnaire developed from the "Infant and Young Child Feeding Practices" nutrition education handbook by United Nations Children's Fund (UNICEF) which was administered pre and post the nutrition education. Data were vetted, coded and subjected to analysis using Statistical Package for Social Sciences (SPSS) version 21.0. Tests were statistically significant at $\mathrm{p} \leq 0.05$.

Results: Below average (42.6\%) of the respondents had good nutritional knowledge on breastfeeding, $42.6 \%$ had average on complementary feeding, while majority $(61.8 \%)$ had good knowledge on health practices in the pretest. The post-intervention test revealed significant improvement in their knowledge where $74.8 \%, 74.0 \%$ and $77.4 \%$ had good nutritional knowledge on breastfeeding, complementary feeding and health practices respectively. Testing the effectiveness of the nutrition education intervention, there was a significant difference between the pre and post nutritional knowledge test scores (p-0.00).

Conclusion: The study population had an average knowledge on breastfeeding and complementary feeding before the nutrition education intervention. The post-education tests result showed improvements on their knowledge from average to good on all the practices. This shows that the nutrition education was effective in improving their maternal nutritional knowledge.
\end{abstract}

Key words: Maternal Nutritional Knowledge, Nutrition Education, Childbearing Age, Breastfeeding, Complementary.

\section{INTRODUCTION}

The main goal of nutrition education is to help people understand important information about health and focus on practical measures to address nutrition needs, as well as the benefits of behavioural changes (1). In line with this, nutrition education intervention for women of childbearing age are meant to provide action-oriented knowledge, skills, behaviours and attitude that will encourage them to adopt optimal infant and young child feeding practices (2). Because, infants and young children are at risk group majorly vulnerable to malnutrition in developing countries (3).

According to the United Nations Department of Economic and Social Affairs (4), childbearing age ranges from 15 to 49 years of age. Information and skills concerning infant and young child feeding practices acquired by women within this age category influences how she will provide nutritional care and practices for the young child, thus determine the nutritional status of the child and the likelihood of developing nutritional related chronic diseases later in life (5).

It has been reported in previous studies $(6,7$ and 8$)$ that there is a correlation between nutritional knowledge of the mothers and the nutritional status, knowledge and habits of their children. More so, a mother's knowledge on food choices, feeding and health care-seeking behaviours are strong determinants of good nutrition outcomes for infant and young children (9). Thus, there is a need to assess the effectiveness of nutrition education intervention on maternal nutritional knowledge among women of childbearing age (15-49 years) in Ikenne Local Government Area of Ogun State. 


\section{MATERIALS AND METHODS}

A descriptive cross-sectional survey was used to conduct this study among women of childbearing age in Ikenne Local Government Area of Ogun State, Nigeria. The sample size of the study was determined using Taro Yamane formula (10) and 115 was obtained.

$$
n=\frac{N}{1+N(e)^{2}}
$$

The 115 women of childbearing age were selected using a simple random sampling technique. Validated questionnaire developed from the "Infant and Young Child Feeding Practices" nutrition education handbook by United Nations Children's Fund (UNICEF) (11) was administered for prenutrition education assessment to know their level of knowledge about infant and young child feeding practices. The questionnaire covers the importance of breastfeeding, complementary feeding, hygiene/other health practices and improving knowledge on breastfeeding and complementary feeding practices. Nutrition education intervention was carried out using the material "Infant and Young Child Feeding Practices" handbook (11) over four weeks before post-nutrition education assessment was carried out to evaluate the effectiveness of the nutrition education on the respondents using the same already developed questionnaire. The information obtained from the validated questionnaires were vetted, coded and subjected to analysis using Statistical Package for Social Sciences (SPSS) version 21.0. Descriptive analysis such as frequency count and percentages of the variables were calculated while Student's T Test was used for inferential statistic of the pre and post test scores.

\section{RESULTS}

The pre and post-test nutritional knowledge level of the respondents were shown in Table 1. Few (16.6\%) had poor knowledge while $42.6 \%$ had good knowledge on breastfeeding practices prior the nutrition education intervention. After they were educated and the same questions on breast feeding practices was administered, the number of respondent with poor knowledge reduced to $2.6 \%$ while good knowledge moved up to $74.8 \%$.

On complementary feeding practices, $16.6 \%$ of the respondents had poor knowledge while $40.8 \%$ of the respondents had good knowledge before the nutrition education intervention was carried out. Post-tests on complementary feeding practices shows that the respondents with poor knowledge were reduced by $9.6 \%$, while the respondents with good knowledge increased to $74.0 \%$.

The pre-tests on health practices showed that $22.6 \%$ of the respondents had poor knowledge while $61.8 \%$ had good knowledge on health practices related to infant and young child feeding. The post-tests showed that the level of poor knowledge reduced to $7.8 \%$ while good knowledge increased to $77.4 \%$.

Table 1: Nutritional Knowledge of the Respondents

\begin{tabular}{lllll}
\hline & Pre-test & \multicolumn{2}{c}{ Post-test } \\
\cline { 2 - 5 } Grade & F & \% & F & \% \\
\hline Breast Feeding Practices & & & & \\
Poor & 19 & 16.6 & 3 & 2.6 \\
Average & 47 & 40.8 & 26 & 22.6 \\
Good & 49 & 42.6 & 86 & 74.8 \\
Total & 115 & 100 & 115 & 100 \\
Complementary Feeding Practices & & & & \\
Poor & 19 & 16.6 & 8 & 7.0 \\
Average & 49 & 42.6 & 22 & 19.0 \\
Good & 47 & 40.8 & 85 & 74.0 \\
Total & 115 & 100 & 115 & 100 \\
Health Practices & & & & \\
Poor & 26 & 22.6 & 9 & 7.8 \\
Average & 18 & 15.6 & 17 & 14.8 \\
Good & 71 & 61.8 & 89 & 77.4 \\
Total & 115 & 100 & 115 & 100 \\
\hline
\end{tabular}

Table 2 shows the association between the pre and post nutritional knowledge test taken by the respondents. There was a significant difference between the means of the pre and post-tests of all the three feeding practices $(\mathrm{p} \leq 0.05)$.

Table 2: Association between Pre and Post-test Nutritional Knowledge

Assessment Score

\begin{tabular}{lllll}
\hline & Pre-test & Post-test & T-test & P-value \\
\cline { 2 - 5 } Variables & Mean \pm SD & Mean \pm SD & & \\
\hline Breast Feeding Practices & $6.99 \pm 2.31$ & $8.60 \pm 1.85$ & -5.823 & 0.00 \\
Complementary Feeding Practices & $5.76 \pm 2.03$ & $7.44 \pm 2.01$ & -6.291 & 0.00 \\
Health Practices & $2.57 \pm 1.24$ & $3.11 \pm 0.96$ & -3.678 & 0.00 \\
\hline
\end{tabular}




\section{DISCUSSION}

Women reproductive age is a crucial stage and the knowledge they acquired determines the kind of care their children get because mothers are primarily responsible for their infant and young child care (12). The results from the study showed that less than half $(42.6 \%)$ of the women had good knowledge on breastfeeding practices, $40.8 \%$ had average knowledge and a few $(16.6 \%)$ had poor knowledge on breastfeeding practices prior to the nutrition education intervention. This is in contrary to a study carried out by Omuemu and Adamu (13) in Federal Capital Territory, Abuja, Nigeria where more than half $(76.7 \%)$ of the mothers had good knowledge on breastfeeding practices which is also in consistent with a study by Drame et al.,(14), where majority of the women were knowledgeable about breastfeeding practices.

In this present study, low percentage $(16.6 \%)$ of the respondents had poor knowledge on complementary feeding practices prior the nutrition education intervention which was relatively low compared to the report of a study carried out in Lagos State, Nigeria by Olatona et al., (15) where about half of the mothers had poor knowledge on complementary feeding practices. However, the results on health practices revealed that majority $(61.8 \%)$ of the women had good knowledge.

The post-tests carried out after the intervention revealed that the respondents' knowledge improved on all the three practices and only a few of the women still had poor knowledge. This outcome agrees with the report of the study conducted by Dewey et al., (16), where an intervention on infants feeding practices was done and improvements were seen subsequently.

The nutrition education intervention was shown to be effective according to the results of this present study when the means of the pre and post-test assessments were compared, it was statistically significant having a p-value $<0.05$. This is in agreement with a study by Sukandar et al., (17) which reported that the intervention in form of nutrition education had a significant effect by improving the nutritional knowledge, attitude and practices among the women that were enrolled for the study.

\section{CONCLUSION}

Less than half of the women of child bearing age in Ikenne Local Government Area of Ogun state had good knowledge on infant and young child feeding practices before the nutrition education intervention. The post-test results of the women showed a significant improvement on their knowledge on all the three practices. Nutrition education intervention played a major role in improving the maternal nutritional knowledge among women of child bearing age in Ikenne Local Government Area of Ogun state.
Ethics approval

Ethical clearance was obtained from Babcock University Health Research Ethics Committee (BUHREC).

\section{Informed Consent}

An informed consent was also obtained from the respondents before the questionnaire was admitted to respondents.

\section{Declaration of interest:}

The authors hereby declare no conflict of interest on this work.

Availability of data and materials

Data and materials are available on request.

Author's contribution

One of the first authors brought the research idea, supervised the work and wrote the manuscript; the second first author was the student that collected the data while the second author assisted in the data analysis.

Funding

The research was self-sponsored by the three authors.

\section{REFERENCES}

1. Food and Nutrition Technical Assistance. Nutrition Assessment, Counselling and Support (NACS): A User's Guide-Module 3: Nutrition Education and Counselling,

Version 2. Washington D.C; 2016.

2. Kulwa, K. B., Verstraeten, R., Bouckaert, K. P., Mamiro, P. S., Kolsteren, P. W., \& Lachat, C. Effectiveness of a nutrition education package in improving feeding practices, dietary adequacy and growth of infants and young children in rural Tanzania: rationale, design and methods of a cluster randomised trial. BMC public health, 2014: 14(1), 1077.

3. Garba MH, Rikong H., Adie E., Soja Nana NM, Kombou M., Fotso MA, Manguelle D., Jallila EA, Alouane L., Mokri R., Beji C., Sairi MH, Oueslati A., and Maire B. Growth retardation in Tunisian preschool children: analysis of probable causes and interpretation of its evolution over the past 25 years. Mediterranean Options, series B 2002: (41): 52-65.

4. United Nations Department of Economic and Social Affairs. Reproductive health policies. Data booklet (ST/ESA/SER.A/396); 2017.

5. Blaylock R. J., Variyam N.J. and Lin B. Maternal nutrition knowledge and children's diet quality and nutrient intakes. Food assistance and nutrition research report No 1. Washington, D.C; 1999.

6. Lee, S., Sung, C., Kim, A., \& Kim, M. A study on nutritional attitude, food behavior and nutritional status according to nutrition knowledge of Korean middle school students. Korean Journal of Community Nutrition, 2000: $5(3), 419-\quad 431$. 
7. Al-Shookri, A., Al-Shukaily, L., Hassan, F., AlSheraji, S., \& Al-Tobi, S. Effect of mothers' nutritional knowledge and attitudes on Omani children's dietary intake. Oman medical journal, 2011: 26(4), 253-257.

8. Yabanci, N., Kisac, I. and Karakus, S. S. The effects of mother's nutritional

knowledge on attitudes and behaviours of children about nutrition. Procedia- social and behavioural sciences. 2014:116: 4477-4481.

9. Fadare, O., Amare, M., Mavrotas, G., Akerele, D., \& Ogunniyi, A. Mother's nutritionrelated knowledge and child nutrition outcomes: Empirical evidence from Nigeria. PloS one, 2019: 14(2), e0212775.

10. Yamane, T. Statistics: An Introductory Analysis, 2nd Edition, New York: Harper and Row; 1967.

11. United Nations Children's Fund (UNICEF). Infant and Young Child Feeding Practices. Programme guide: 2011. https://www.unicef.org/nutrition/files/Final_I YCF_programming_guide_2011.

12. Özdoğan, Y., Uçar, A., Akan, L. S., Yılmaz, M. V., Sürücüoğlu, M. S., Pınar, F., \& Özçelik, A. Ö. Nutritional knowledge of mothers with children aged between 0-24 months. J Food Agric Environ, 2012: 10(1), 173-5.
13. Omuemu, V., \& Adamu, S. Assessment of breastfeeding knowledge and practices among working mothers in the federal capital territory Nigeria. Int J Community Med Public Health, 2018: 6(1), 20-29.

14. Drame L., Bouazza G., Laamiri F.Z., Chahid N., Aguenaou H., and Barkat A. Study of mothers' knowledge and practices related to the feeding of their children during the first six months of life. Trends in Medicine, 2018: 18(5): $1-4$.

15. Olatona, F. A., Adenihun, J. O., Aderibigbe, S. A., \& Adeniyi, O. F. Complementary feeding knowledge, practices, and dietary diversity among mothers of under-five children in an urban community in Lagos State, Nigeria. Int J. MCH AIDS, 2017: 6(1): 46-59.

16. Dewey, K. G., \& Adu-Afarwuah, S. Systematic review of the efficacy and effectiveness of complementary feeding interventions in developing countries. Matern Child Nutr, 2008: 4: 24-85.

17. Sukandar, D., Khomsan, A., Anwar, F., Riyadi, H., \& Mudjajanto, E. S. Nutrition Knowledge, Attitude, and Practice of Mothers and Children Nutritional Status Improved after Five Months Nutrition Education Intervention. Int J Sci Basic Appl Res, 2015: 23(2), 424-42. 